Check for updates

Cite this: Chem. Commun., 2021 57,12532

Received 1st October 2021

Accepted 26th October 2021

DOI: $10.1039 / \mathrm{d} 1 \mathrm{cc} 05557 \mathrm{~g}$

rsc.li/chemcomm

\section{Attempted reduction of a carbazolyl-diiodoalane $\dagger$}

\author{
Alexander Hinz (D)* and Maximilian P. Müller
}

We report details of our attempts to reduce the bulky carbazolyl diiodoalane $\left[R-\mathrm{All}_{2}\right]$. The reducing agents employed include $\mathrm{KC}_{8}$, $\mathrm{Cp}_{2}{ }_{2} \mathrm{Co}$ and the $\mathrm{Mg}(\mathrm{l})$ compound $\left[\left({ }^{\mathrm{Mes}} \mathrm{BDI}\right) \mathrm{Mg}\right]_{2}$. The use of $\mathrm{KC}_{8}$ allowed the spectroscopic observation of the alanediyl [R-Al]. With $\mathrm{Cp}{ }_{2} \mathrm{Co}$ as the reducing agent, the alanediyl [R-Al] was obtained as a crystalline material in low yield, but paramagnetic impurities remained. When diiodoalane $\left[\mathrm{R}-\mathrm{All}_{2}\right]$ was treated with $\left[\left({ }^{\mathrm{Mes}} \mathrm{BDI}\right)-\right.$ $\mathrm{Mgl}_{2}$, no reduction but a 2:1 addition was observed.

Aluminium(I) chemistry has seen remarkable progress in the last few years after initial discoveries of $\left[\mathrm{AlCp}^{*}\right]_{4}$ (Scheme 1, A) by Schnöckel and [( ${ }^{\text {Dipp }}$ BDI $\left.) A l\right]$ (B) by Roesky. ${ }^{1,2}$ Both compounds were utilised in further reactions, spanning both coordination chemistry and the activation of small molecules. ${ }^{3-5}$ A new impulse was given by attempts of generating dialumenes, where Tokitoh obtained hidden examples ${ }^{6,7}$ and Inoue succeeded in synthesising the base-stabilised dialumene $(\mathbf{C}){ }^{8}$ Anionic aluminium nucleophiles have been in the focus of interest since the groups of Aldridge and Goicoechea reported on the first example bearing a xanthene-based diamido substituent (D). Later, other examples without O-donor moieties or even N-substituents were reported by Yamashita, Kinjo, Coles, Harder and Hill. ${ }^{9-13}$ Braunschweig and coworkers utilised a bulky cyclopentadienyl derivative to stabilise the monomeric $\mathrm{Al}(\mathrm{I})$ compound $\mathbf{E}^{14}$ The quest for a genuine mono-coordinated $\mathrm{Al}(\mathrm{I})$ compound is still ongoing. The group of Power was the first to succeed when they employed the bulkiest terphenyl substituent available and prepared the alanediyl $\mathbf{F}^{15,16}$

Our interest was directed in a similar direction, but instead of a terphenyl substituent we attempted to use the carbazolebased ligand R. After establishing a bulky carbazole (R) as the

Karlsruher Institut für Technologie (KIT), Institut für Anorganische Chemie (AOC), Engesserstraße 15, Karlsruhe D-76131, Germany.E-mail: alexander.hinz@kit.edu $\dagger$ Electronic supplementary information (ESI) available. CCDC 2108296-2108299. For ESI and crystallographic data in CIF or other electronic format see DOI: $10.1039 / \mathrm{d} 1 \mathrm{cc} 05557 \mathrm{~g}$ main scaffold for our endeavours in main-group chemistry, we initially investigated group 14 derivatives (Scheme 1, bottom). ${ }^{17,18}$ These efforts lead to quasi-monocoordinate divalent cations with the general formula $[\mathrm{R}-\mathrm{E}]^{+}(\mathrm{E}=\mathrm{Si}, \mathrm{Ge}, \mathrm{Sn}, \mathrm{Pb})$ in salts with the weakly coordinating anion $\left[\mathrm{Al}\left(\mathrm{OC}_{4} \mathrm{~F}_{9}\right)_{4}\right]^{-}$. Subsequently, the synthesis of the isovalent electronic molecule [R-Al] was targeted, incorporating $\mathrm{Al}(\mathrm{I})$ instead of, for instance, Si(II). As recently Zhang and Liu published the synthesis of the free carbazolyl aluminylene [R-Al] and its coordination behaviour towards transition metal complexes, ${ }^{19}$ we are prompted to disseminate our current results with respect to carbazolyl aluminium chemistry and to conclude this direction of work in our group.

Before starting any experimental work, we studied the possible decomposition pathways of the carbazolyl-bearing compound [R-Al] in silico. The terminal alanediyl could in principle be inserted into either of the $\left(\mathrm{sp}^{2}\right) \mathrm{C}-\mathrm{H}$ or $\left(\mathrm{sp}^{2}\right)$ $\mathrm{C}-\mathrm{C}\left(\mathrm{sp}^{2}\right)$ bonds of the flanking arenes. Both reactions would lead to minima on the energy hypersurface, among which the $\mathrm{C}-\mathrm{C}$ insertion product is thermodynamically disfavoured over [R-Al] by $+124.5 \mathrm{~kJ} \mathrm{~mol}^{-1}$, while the $\mathrm{C}-\mathrm{H}$ insertion product is favoured by $-38.6 \mathrm{~kJ} \mathrm{~mol}^{-1}$. In both cases, however, the activation barrier for the process is very large $(\mathrm{C}-\mathrm{C}$ insertion,

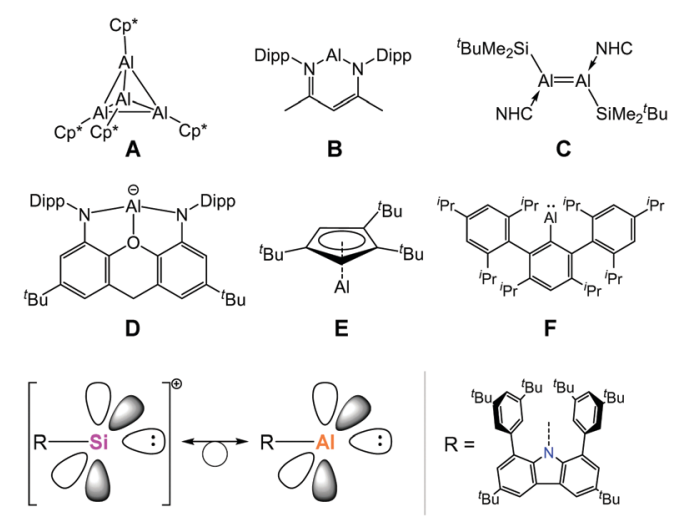

Scheme 1 Known Al(I) species and carbazolyl compounds. 


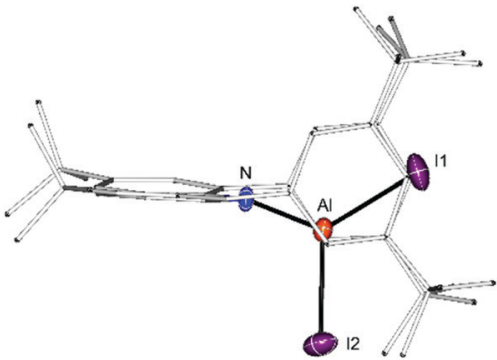

Fig. 1 Non-disordered molecular structure of $\left[\mathrm{R}-\mathrm{All}_{2}\right]$ in crystals of the benzene solvate; thermal ellipsoids at $50 \%$ probability at $200 \mathrm{~K}$.

280.2; C-H insertion, $248.5 \mathrm{~kJ} \mathrm{~mol}^{-1}$ ), so it is not expected to take place under ambient conditions. This situation is comparable to the $[\mathrm{R}-\mathrm{Si}]^{+}$cation (see the ESI, $\uparrow$ Computational details).

With these encouraging data in hand, we initiated practical work efforts. The diiodoalane $\left[\mathrm{R}-\mathrm{AlI}_{2}\right]$ can be prepared by metathesis of potassium carbazolide $[\mathrm{R}-\mathrm{K}]$ with $\mathrm{AlI}_{3}$ in toluene, in analogy to the preparation of carbazolyl trihalosilanes. The reaction mixture usually adopts a dark green colour, but after filtration and evaporation of the solvent this by-product can be removed by washing with $n$-hexane. $\left[\mathrm{R}-\mathrm{AlI}_{2}\right]$ is surprisingly poorly soluble in hexane and toluene and decomposes in THF at ambient temperature within minutes, but can be crystallised from hot toluene to yield a colourless crystalline material. In these crystals obtained from the toluene solution, the $\mathrm{AlI}_{2}$ moiety is multiply disordered (Fig. S4, ESI $\dagger$ ). Remarkably, from a sample of $\left[\mathrm{R}-\mathrm{AlI}_{2}\right]$ recrystallised from benzene, the solvate $\left[\mathrm{R}-\mathrm{AlI}_{2}\right] \cdot \mathrm{C}_{6} \mathrm{H}_{6}$ could be obtained, in which no $\mathrm{AlI}_{2}$ disorder was found (Fig. 1). In this molecular structure, the $\mathrm{N}-\mathrm{Al}$ bond length amounts to $1.830(3) \AA$, and the $\mathrm{Al}$ atom possesses a short contact to one $o$-C atom of the flanking arene of 2.584(4) $\AA$, illustrating its acidity. In solution, however, this contact is fluxional, as all NMR resonances for the aryl- ${ }^{t} \mathrm{Bu}$ groups are magnetically equivalent (see the ESI $\dagger$ 2.1).

With $\left[\mathrm{R}-\mathrm{AlI}_{2}\right]$ available, we made attempts to carry out reduction. The initial attempts were conducted with $\mathrm{KC}_{8}$ as the reducing agent (Scheme 2). However, this reduction proved problematic: while diiodoalane $\left[\mathrm{R}-\mathrm{AlI}_{2}\right]$ was reduced to [R-Al], also the alanediyl [R-Al] was reduced, and potassium carbazolide $[\mathrm{R}-\mathrm{K}]$ was formed. With stepwise addition of small portions of $\mathrm{KC}_{8}$ and waiting for the reduction to complete, a maximum spectroscopic yield of $[\mathrm{R}-\mathrm{Al}]$ of $55 \%$ was obtained (Fig. S6, $\mathrm{ESI} \dagger)$. From this mixture, the product [R-Al] could not be

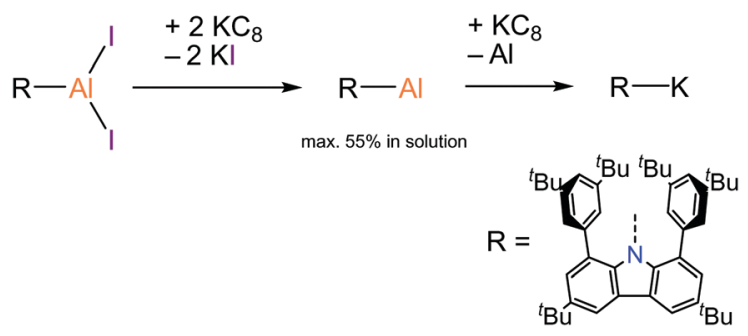

Scheme 2 Reduction of $\mathrm{RAll}_{2}$ with $\mathrm{KC}_{8}$. isolated. However, spectroscopic characterisation was successful. ${ }^{1} \mathrm{H}$ NMR spectra indicate $C_{2 \mathrm{v}}$ symmetry in the product molecule, i.e. all $o^{-}{ }^{t} \mathrm{Bu}$ groups are magnetically equivalent. Furthermore, the ${ }^{15} \mathrm{~N}$ NMR spectra, which showed a marked downfield shift of the carbazolyl-N resonance for the monocoordinated silicon cation $[\mathrm{R}-\mathrm{Si}]^{+}$, show a similar behaviour here. The ${ }^{15} \mathrm{~N}$ NMR resonance of $\left[\mathrm{R}-\mathrm{AlI}_{2}\right]$ at $132.8 \mathrm{ppm}$ is shifted downfield by 50 ppm to 183.0 ppm upon reduction. A comparable phenomenon was observed in the deprotonation of $[\mathrm{R}-\mathrm{H}]$ and the halide abstraction from [R-SiBr] yielding $[\mathrm{R}-\mathrm{K}]$ and $[\mathrm{R}-\mathrm{Si}]^{+}$, respectively. ${ }^{17,20}$ This can be rationalised by considering delocalising the lone pair of electrons at $\mathrm{N}$ into suitable acceptor orbitals (Fig. S14, ESI $\dagger$ ). In [R-AlI $\left.{ }_{2}\right]$ and [R-SiBr], Al and $\mathrm{Si}$ possess an unoccupied $\mathrm{p}$ orbital in the plane of the carbazole scaffold and thus orthogonal to the occupied $\mathrm{p}$ orbital at $\mathrm{N}$, while in $[\mathrm{R}-\mathrm{H}]$ no $\mathrm{p}$ orbital contribution is relevant at the $\mathrm{N}-\mathrm{H}$. Upon deprotonation and formation of [R-Al], [R-Si] ${ }^{+}$and [R-K], a p-type acceptor orbital becomes available and thus the $\mathrm{N}$ atom is magnetically deshielded. This is also mirrored in an increasing computed anisotropy of the shielding tensor and a marked change in its YY component (see the ESI $\dagger$ 4.2). Therefore, the ${ }^{15} \mathrm{~N}$ NMR resonance also corroborates the formal coordination number 1 of the metal attached to the carbazolyl substituent in the reduction product [R-Al]. The ${ }^{27} \mathrm{Al}$ NMR shift would be even more diagnostic as it was estimated at +80 ppm by DFT methods, but could not be observed.

In another experiment, we employed $\mathrm{Cp}^{*}{ }_{2} \mathrm{Co}$ as the reducing agent. The reaction mixture immediately turned dark brown, indicating a reaction had taken place. After filtration, evaporation of the solvent, and washing, a few orange crystals were obtained. The reaction could only be carried out successfully on a very small scale, yielding only a few crystals each time. Reactions carried out on a larger scale that should have yielded several hundred milligrams of the product did not allow isolation of [R-Al] at all. Difficulties arise from ensuing paramagnetic impurities which have to be removed by crystallisation. Thus, both reducing agents show poorer performance than $\mathrm{K} / \mathrm{KI}$ which was employed by Liu and allowed isolation of $[\mathrm{R}-\mathrm{Al}]$ in $67 \%$ yield. $^{19}$

The XRD data for [R-Al] showed its mono-ligated aluminium structural motif immediately after structure solution, but shows significant disorder (Fig. S11, ESI $\dagger$ ). In the major part (Fig. 2), the metrics show a N-Al bond length of 1.908(3) $\AA$ as well as the four shortest $\mathrm{Al}-\mathrm{C}$ contacts to the $o$-C atoms of the flanking arenes of 3.015(3), 3.019(3), 3.178(3) and 3.175(3) A.. These data are in agreement with computational predictions (N-Al $1.950 \AA$, all Al-C contacts > $3 \AA$ ) and the observed results of the Liu group. ${ }^{19}$

In another attempt of reduction of the diiodoalane [R-AlI $\left.{ }_{2}\right]$, Jones' $\mathrm{Mg}(\mathrm{I})$ compound $\left[\left({ }^{\mathrm{Mes}} \mathrm{BDI}\right) \mathrm{Mg}\right]_{2}$ was employed as the reducing agent (Scheme 3), ${ }^{21,22}$ as alanates and alane-carbene adducts are known to be reduced with this agent. ${ }^{23,24}$ Contrary to the expectation of a $1: 1$ reaction, even in a $1: 1$ reaction mixture, 2:1 consumption of the starting materials was observed with complex NMR characteristics indicating a 


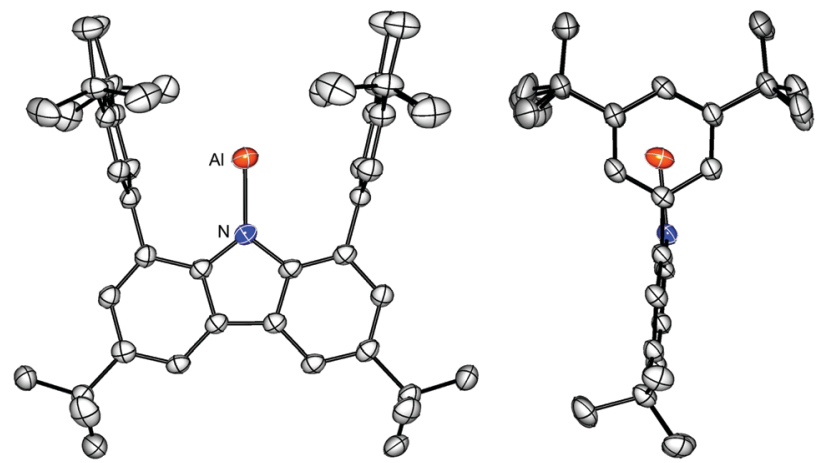

Fig. 2 Molecular structure of [R-Al]. Thermal ellipsoids at $50 \%$ probability at $150 \mathrm{~K}$.

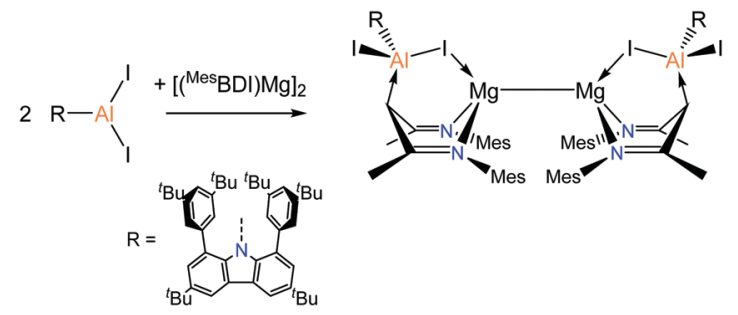

Scheme 3 Reaction of $\mathrm{RAll}_{2}$ with $\left[\left({ }^{\mathrm{Mes}} \mathrm{BDI}\right) \mathrm{Mg}\right]_{2}$.

product of low symmetry with respect to the carbazole moiety. The reaction was repeated with a 2:1 stoichiometry and allowed the isolation of the orange crystalline product after filtration and concentration in $45 \%$ yield. The XRD analysis revealed that the addition of the diiodoalane across both $\left[\left({ }^{\mathrm{Mes}} \mathrm{BDI}\right) \mathrm{Mg}\right]$ moieties of the $\mathrm{Mg}(\mathrm{I})$ starting material had taken place (Fig. 3), and thus a 2:1 reaction could occur and yield $\left[\left(\mathrm{RAlI}_{2}\right)_{2}\left\{\left({ }^{\mathrm{Mes}} \mathrm{BDI}\right) \mathrm{Mg}\right\}_{2}\right]$. This reaction left the $\mathrm{Mg}-\mathrm{Mg}$ bond intact and no reduction of the alane was achieved. This reactivity differs from the literature known reactions of $\mathrm{Mg}(\mathrm{I})$ with $\mathrm{Al}(\mathrm{III})^{23,24}$ because in this instance the acidity of the alane is unquenched.

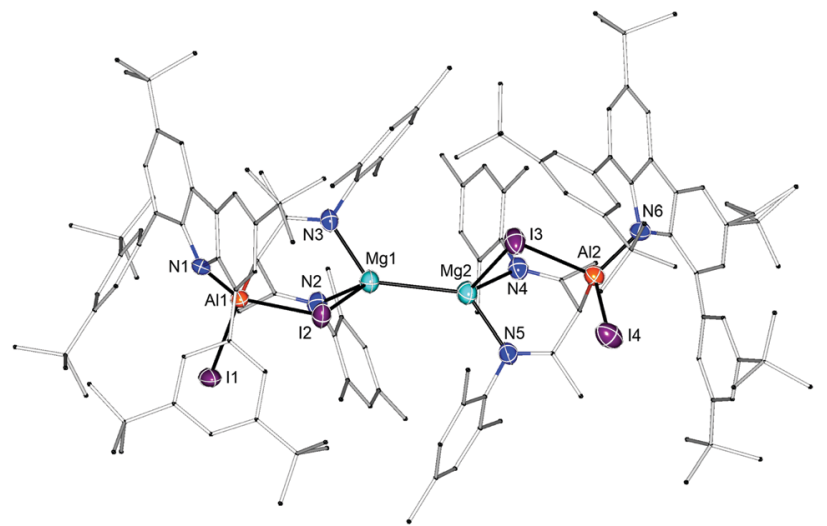

Fig. 3 Molecular structures of [(RAll $\left.)_{2}\left\{\left({ }^{\text {Mes }} \mathrm{BDI}\right) M g\right\}_{2}\right]$. Thermal ellipsoids at $50 \%$ probability at $110 \mathrm{~K}$.
The basicity of the gamma-C atom of the BDI scaffold was demonstrated in several examples of d-block metal complexes with $\mathrm{H}^{+}$as the electrophile, ${ }^{25-31}$ but was not yet observed in the class of $\mathrm{Mg}(\mathrm{I})$ compounds. However, $\left[\{(\mathrm{BDI}) \mathrm{Mg}\}_{2}\right]$ were involved in acid-base reactions, where coordination of Lewis base ethers, pyridines or carbenes was observed at the acidic $\mathrm{Mg}$ atoms which could also boost the reactivity. ${ }^{32-34}$

The molecular structure of $\left[\left(\mathrm{RAlI}_{2}\right)_{2}\left\{\left({ }^{\mathrm{Mes}} \mathrm{BDI}\right) \mathrm{Mg}\right\}_{2}\right]$ (Fig. 3) shows the $\mathrm{Mg}-\mathrm{Mg}$ bond with a length of 2.851(3) $\AA$ which is nearly unchanged compared to original $\mathrm{Mg}(\mathrm{I})$ compounds $(2.8457(8) \AA)^{21}{ }^{21}$ The newly formed Al-C bonds are of 2.079(6) and 2.098(6) A lengths, respectively. The terminal Al-I bonds with lengths of 2.521(2) and 2.505(2) $\AA$ are shorter than the respective bonds to the bridging iodides (2.608(2) and 2.592(2) ̊). The Mg-I contacts are long and amount to 2.926(2) and 2.953(2) $\AA$, which are longer than that in $\left[\left({ }^{\mathrm{Mes}} \mathrm{BDI}\right) \mathrm{MgI}\left(\mathrm{OEt}_{2}\right)\right]$ (2.6915(9) $\left.\AA\right) .{ }^{32}$ The NMR spectroscopic properties are consistent with the molecular structure in the crystal. There are six distinct ${ }^{t} \mathrm{Bu}$ group resonances as well six inequivalent methyl group resonances. In the ${ }^{15} \mathrm{~N}$ NMR spectrum, the resonances of the BDI scaffold could be found at 257.8 and $268.4 \mathrm{ppm}$, while the carbazolyl-N NMR resonance could not be observed.

Analysis of the frontier orbitals of this compound shows a localised (s-s) $\sigma$-bond in the HOMO and a set of two quasidegenerate unoccupied orbitals delocalised over one BDI and carbazole moiety each (Fig. 4). The HOMO energy of $-4.197 \mathrm{eV}$ is elevated by $0.411 \mathrm{eV}$ compared to the original $\left[\left\{\left({ }^{\mathrm{Mes}} \mathrm{BDI}\right) \mathrm{Mg}\right\}_{2}\right]$, while the LUMO energy is essentially unchanged. This accounts for a slightly narrower HOMOLUMO gap in $\left[\left(\mathrm{RAlI}_{2}\right)_{2}\left\{\left({ }^{\mathrm{Mes}} \mathrm{BDI}\right) \mathrm{Mg}\right\}_{2}\right]$, and therefore it is more orange than yellow in colour. An NBO analysis of $\left[\left(\mathrm{RAlI}_{2}\right)_{2}\right.$ $\left.\left\{\left({ }^{\mathrm{Mes}} \mathrm{BDI}\right) \mathrm{Mg}\right\}_{2}\right]$ shows a largely unchanged charge distribution

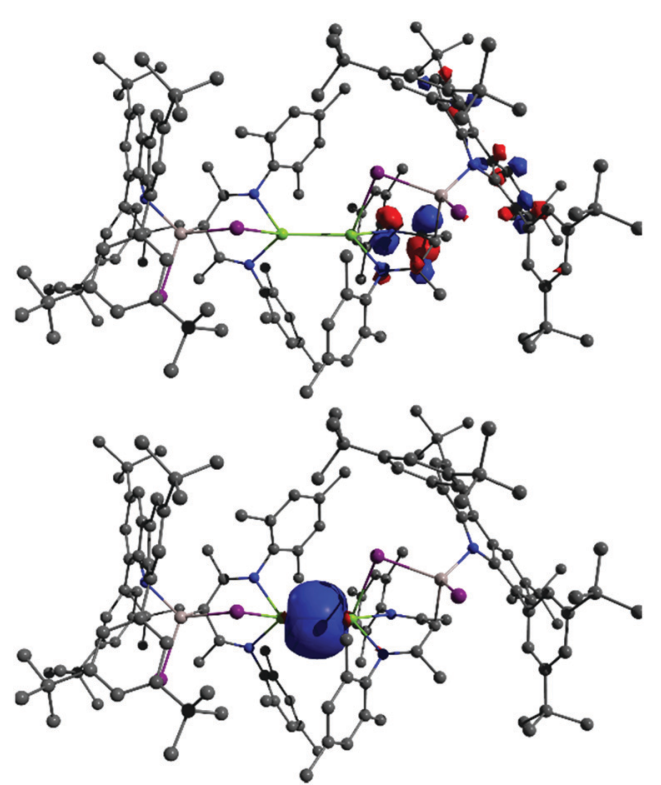

Fig. 4 Frontier orbitals of $\left[\left(\mathrm{RAll}_{2}\right)_{2}\left\{\left({ }^{\mathrm{Mes}} \mathrm{BDI}\right) \mathrm{Mg}\right\}_{2}\right]$ (top: LUMO, bottom: HOMO). 
upon adduct formation (Fig. S15, ESI $\dagger$ ) with the largest changes observed in the NCCCN moiety of the BDI scaffold, where more negative charge is accumulated at the $\gamma$-C. The bonds involving the aluminium atoms show strongly polarised interactions, with contributions of only $14-23 \%$ of $\mathrm{Al}$ to the NBO $\sigma$-orbitals (ESI $\dagger 4.3$ ). There is no NBO $\sigma$-bond between $\mathrm{Mg}$ and the bridging iodide, but second-order perturbation theory analysis shows several weak delocalisations of I lone pairs to $\mathrm{Mg}$. Comparison of the topological characteristics of both the Al-I and $\mathrm{Mg}-\mathrm{I}$ interactions shows a bond critical point, where the properties differ significantly (ESI $\dagger 4.3$ ). Both the electron density $\rho$ and the Laplacian $\nabla(\rho)$ show lower values for Mg-I ( $\rho .017, \nabla(\rho) 0.060)$ than for Al-I $(\rho 0.046, \nabla(\rho)$ 0.096), indicating a weaker interaction.

We reported on the details of the application of classic reducing agents in the reaction with carbazolyl diiodoalane $\left[\mathrm{R}-\mathrm{AlI}_{2}\right]$. This allowed the generation and characterisation of [R-Al], but no large-scale preparations. When $\mathrm{Mg}(\mathrm{I})$ compounds were employed in the reaction, no reduction but an addition reaction was observed. This emphasises the relevance of finding suitable reducing agents in the preparation of low valent compounds.

This work was financially supported by the Fonds der Chemischen Industrie through a Liebig Fellowship for A. H. and a Kekule Fellowship for M. P. M. as well as by the German Research Foundation (DFG) through the Emmy Noether Programme (HI 2063/1-1). We thank Prof. Frank Breher and Prof. Peter Roesky for continuous support. This work was carried out with the support of the Karlsruhe Nano Micro Facility (KNMF), a Helmholtz Research Infrastructure at Karlsruhe Institute of Technology (KIT), and Prof. Dieter Fenske is gratefully acknowledged for help with XRD. We acknowledge support by the state of Baden-Württemberg through bwHPC and DFG through grant no. INST 40/467-1 FUGG (JUSTUS cluster).

\section{Conflicts of interest}

There are no conflicts to declare.

\section{Notes and references}

1 C. Dohmeier, C. Robl, M. Tacke and H. Schnöckel, Angew. Chem., Int. Ed. Engl., 1991, 30, 564-565.

2 C. Cui, H. W. Roesky, H. Schmidt, M. Noltemeyer, H. Hao and F. Cimpoesu, Angew. Chem., 2000, 39, 4274-4276.
3 M. T. Gamer, P. W. Roesky, S. N. Konchenko, P. Nava and R. Ahlrichs, Angew. Chem., Int. Ed., 2006, 45, 4447-4451.

4 G. He, O. Shynkaruk, M. W. Lui and E. Rivard, Chem. Rev., 2014, 114, 7815-7880.

5 T. Chu and G. I. Nikonov, Chem. Rev., 2018, 118, 3608-3680.

6 T. Agou, K. Nagata and N. Tokitoh, Angew. Chem., Int. Ed., 2013, 52, 10818-10821.

7 K. Nagata, T. Murosaki, T. Agou, T. Sasamori, T. Matsuo and N. Tokitoh, Angew. Chem., Int. Ed., 2016, 1-5.

8 P. Bag, A. Porzelt, P. J. Altmann and S. Inoue, J. Am. Chem. Soc., 2017, 139, 14384-14387.

9 J. Hicks, P. Vasko, J. M. Goicoechea and S. Aldridge, Nature, 2018, 557, 92-95.

10 S. Kurumada, S. Takamori and M. Yamashita, Nat. Chem., 2019, 12, 10-13.

11 K. Koshino and R. Kinjo, J. Am. Chem. Soc., 2020, 142, 9057-9062.

12 R. J. Schwamm, M. P. Coles, M. S. Hill, M. F. Mahon, C. L. McMullin, N. A. Rajabi and A. S. S. Wilson, Angew. Chem., Int. Ed., 2020, 59, 3928-3932.

13 S. Grams, J. Eyselein, J. Langer, C. Färber and S. Harder, Angew. Chem., 2020, 132, 16116-16120.

14 A. Hofmann, T. Tröster, T. Kupfer and H. Braunschweig, Chem. Sci., $2019,10,3421-3428$.

15 J. D. Queen, A. Lehmann, J. C. Fettinger, H. M. Tuononen and P. P. Power, J. Am. Chem. Soc., 2020, 142, 20554-20559.

16 J. D. Queen, S. Irvankoski, J. C. Fettinger, H. M. Tuononen and P. P. Power, J. Am. Chem. Soc., 2021, 143, 6351-6356.

17 A. Hinz, Chem. - Eur. J., 2019, 25, 3267-3271.

18 A. Hinz, Angew. Chem., Int. Ed., 2020, 59, 19065-19069.

19 X. Zhang and L. L. Liu, Angew. Chem., Int. Ed., 2021, DOI: 10.1002/ anie. 202111975.

20 A. Hinz, Angew. Chem., Int. Ed., 2020, 59, 19065-19069.

21 S. P. Green, C. Jones and A. Stasch, Science, 2007, 318, 1754-1757.

22 J. Hicks, M. Juckel, A. Paparo, D. Dange and C. Jones, Organometallics, 2018, 37, 4810-4813.

23 S. J. Bonyhady, D. Collis, G. Frenking, N. Holzmann, C. Jones and A. Stasch, Nat. Chem., 2010, 2, 865-869.

24 C. Jones, Nat. Rev. Chem., 2017, 1, 0059.

25 C. Camp and J. Arnold, Dalton Trans., 2016, 45, 14462-14498.

26 D. W. Shaffer, S. A. Ryken, R. A. Zarkesh and A. F. Heyduk, Inorg. Chem., 2012, 51, 12122-12131.

27 G. Bai, P. Wei, A. Das and D. W. Stephan, Organometallics, 2006, 25, $5870-5878$

28 A. Hadzovic, J. Janetzko and D. Song, Dalton Trans., 2008, 3279-3281.

29 D. F. Schreiber, C. O'Connor, C. Grave, H. Müller-Bunz, R. Scopelliti, P. J. Dyson and A. D. Phillips, Organometallics, 2013, 32, 7345-7356.

30 A. Venugopal, M. K. Ghosh, H. Jürgens, K. W. Törnroos, O. Swang, M. Tilset and R. H. Heyn, Organometallics, 2010, 29, 2248-2253.

31 C. Camp, L. Maron, R. G. Bergman and J. Arnold, J. Am. Chem. Soc., 2014, 136, 17652-17661.

32 S. J. Bonyhady, C. Jones, S. Nembenna, A. Stasch, A. J. Edwards and G. J. McIntyre, Chem. - Eur. J., 2010, 16, 938-955.

33 K. Yuvaraj, I. Douair, D. D. L. Jones, L. Maron and C. Jones, Chem. Sci., 2020, 11, 3516-3522.

34 K. Yuvaraj, I. Douair, A. Paparo, L. Maron and C. Jones, J. Am. Chem. Soc., 2019, 141, 8764-8768. 